\title{
Analysis of gastroscopy results among healthy people undergoing a medical checkup: a retrospective study
}

Haosu Huang, Yanting Rong, Meng Wang, Zimeng Guo, Yanghua Yu, Zhenpu Long, Xiaoxiao Chen, Hanyue Wang, Junjie Ding, Lu Yan and Jie Peng ${ }^{*}$

\begin{abstract}
Background: The association of upper gastrointestinal endoscopic findings with sex, age, and Helicobacter pylori infection in asymptomatic healthy people is unclear. The aim of this study was to retrospectively determine the associations of upper gastrointestinal endoscopic findings in asymptomatic healthy people with sex, age, and H. pylori infection.

Methods: A retrospective study was conducted on 2923 patients from a health examination center in Xiangya Hospital between September 2015 and September 2019. Data on sex, age, H. pylori infection, and gastroscopy results were collected.

Results: Among 2923 asymptomatic patients who underwent gastroscopy, 2911 (99.59\%) had abnormal results. The top three results were chronic gastritis (95.11\%), peptic ulcer (17.45\%), and duodenitis (9.17\%). Inflammation of the gastric mucosa in chronic gastritis was more severe in the H. pylori-positive group. The incidence of peptic ulcer decreased with increasing age and was higher in men, patients aged <30years, and H. pylori-positive patients. The incidence of polyps was higher in women (9.54\%) than in men (5.94\%), and the incidence in individuals aged $\geq 60$ years $(11.63 \%)$ was higher than that in those aged $<60$ years $(6.83 \%)$. The pathological results of gastric polyps depended on the location of the lesion.

Conclusion: The incidence of abnormal upper gastrointestinal endoscopic results is high in asymptomatic healthy people undergoing a check-up and is associated with sex, age, and H. pylori infection. Gastroscopy should be considered part of a routine health check.
\end{abstract}

Keywords: Abnormal upper gastrointestinal endoscopic results, Gastroscopy, Health check, Screening

\section{Background}

Physical examination in the outpatient setting is a valuable tool. Even in settings where there is a lack of evidence, such as the annual physical examination of the asymptomatic adult, physical examination is beneficial for the physician-patient relationship. When a patient has specific symptoms, physical examination can help narrow

*Correspondence: pengjie2014@csu.edu.cn

Department of Gastroenterology, Xiangya Hospital, Central South

University, 87 Xiangya Road, Changsha 410008, Hunan Province, China down or, in many cases, establish a diagnosis [1]. Physical examination is an important feature of healthcare encounters and is considered a key aspect of diagnosis and treatment planning [2]. In an annual physical examination, imaging and laboratory tests are easily available, including gastroscopy.

Gastroscopy enables physicians to visualize a variety of upper gastrointestinal lesions, particularly small lesions [3]. Employing gastroscopy is essential for the diagnosis of gastric and upper gastrointestinal diseases. Nevertheless, gastroscopy is generally indicated only in case of 
symptomatic patients. In asymptomatic healthy people, routine endoscopy remains controversial. As the pace of modern life continues to accelerate, the pressures from work, family, and society are constantly increasing. People find it difficult to maintain good eating patterns, and the phenomenon of overeating is common. With the ever growing economic development of society, gastroscopy is becoming increasingly common as a physical examination item; screening for upper gastrointestinal lesions have therefore become a regular part of medical examinations. In the context of routine physical examinations, it is possible to screen for abnormal upper gastrointestinal endoscopic results and to achieve early detection, prevention, and diagnosis.

In this study, we sought to clarify the incidence of various abnormal upper gastrointestinal endoscopic results and to compare how they varied according to sex and age in healthy, asymptomatic people undergoing a checkup. Moreover, we also evaluated the association between the incidence of abnormal endoscopic results and Helicobacter pylori $(\mathrm{Hp})$ infection, as well as the association between pathological results and lesion location.

\section{Methods}

\section{Subjects}

This retrospective study included the results from healthy individuals age 14-78 years who underwent gastroscopy at a health examination center at Xiangya Hospital (a tertiary endoscopic center) between September 2015 and September 2019. There were 2923 subjects (1718 men and 1205 women). The mean age was $46.4 \pm 10.3$ years. Subjects were divided into five subgroups according to age ( $<30$ years, $30-39$ years, $40-49$ years, $50-59$ years, and $\geq 60$ years). The study protocol was approved by the Ethic Committee of the Xiangya Hospital of Central South University (No: 201912541). Instruments used included an Olympus-260 endoscope. Patients were fasted for $8 \mathrm{~h}$ and water deprivation was performed for $4 \mathrm{~h}$ before treatment. Oral administration of dacronine hydrochloride $(10 \mathrm{ml}: 0.1 \mathrm{~g})$ was performed before gastroscopy for mucosal lubrication and anesthesia. Patients who underwent painless gastroscopy were given balanced anesthesia before gastroscopy. Balanced anesthesia was not performed for patients who underwent ordinary gastroscopy.

\section{Inclusion criteria}

The subjects who were referred for gastroscopy over a 4-year period (September 2015 to September 2019) and had complete basic information were eligible for the study. The health examination center sent questionnaires to patients before the health check, including filling in uncomfortable symptoms and medical history.
Asymptomatic individuals were determined according to the questionnaire's results and systemic physical examination. At the outset, we excluded patients with symptoms of the upper digestive tract, including acid reflux, belching, or heartburn and those who had a definite diagnosis of upper gastrointestinal disease.

\section{Data collection}

The basic data collected at the endoscopy center included sex, age, detection of $\mathrm{Hp}$, and gastroscopy results. The pathological examination provided data regarding gastroscopy diagnosis, biopsy site, and pathological diagnosis.

\section{Diagnosis}

Current practice guidelines advocate testing patients for Hp infection primarily using non-invasive methods, including the urea breath test (UBT), and invasive methods, including histology examination [4]. Hp tests in the study included UBT and histological examination of specimens obtained using gastroscopy. For clinical diagnosis, 2-3 pieces of tissue were taken for biopsy at the gastric antrum, lesser curvature of stomach, and gastric body sites. Biopsy was also taken at the suspected lesion. Endoscopy combined with histopathological examination can diagnose the two basic types of chronic gastritis: chronic non-atrophic gastritis and chronic atrophic gastritis. The endoscopic findings of chronic non-atrophic gastritis included mucosal erythema, bleeding mucosal spots or plaques, and mucosal roughness, either with or without edema, congestion, or exudation. The endoscopic findings of chronic atrophic gastritis included mixed red and white shades of mucosa dominated by white mucosa, flat or even absent folding, and exposure of part of the mucosal blood vessels [5]. The final diagnosis of chronic atrophic gastritis was based on the pathological diagnosis. The pathologic diagnosis of chronic gastritis was in accordance with the Chinese consensus on chronic gastritis (2017, Shanghai) [6]. The criteria of histopathological grading are as follows: in mild cases, the lamina propria of the mucosa is infiltrated with few neutrophils; in moderate cases, more neutrophils are seen in the mucosal layer and can also be seen in between superficial epithelial cells, pit epithelial cells and glandular epithelial cells. In severe cases, denser infiltration of neutrophils, or abscess on pits can be seen in addition to what is seen in moderate activity. Other upper gastrointestinal lesions were diagnosed according to relevant guidelines.

\section{Statistical analysis}

SPSS 26.0 statistical software (SPSS, Inc., Chicago, IL, USA) was used to perform the statistical analyses. Measurement data are expressed as mean $\pm S D$, and 
comparisons between groups were performed using $\mathrm{t}$-tests. Countable data were analyzed using the $x^{2}$ test. $p<0.05$ indicated statistically significant differences.

\section{Results}

Overall results for abnormal upper gastrointestinal endoscopic results

Normal upper gastrointestinal endoscopic results were observed in 12 patients (0.41\%; 4 men and 8 women). The remaining 2911 patients (99.59\%) had abnormal upper gastrointestinal endoscopic results (1714 men and 1197 women). There were 184 patients in the $<30$ years age group, 462 patients in the $30-39$ years age group, and 1100 patients in the $40-49$ year age group. There were 816 patients aged 50-59 years, and 361 patients older than 60 years. A total of $976 \mathrm{Hp}$ tests were completed and 354 cases were positive (36.27\%).

\section{Distribution of lesions detected in the upper digestive tract}

Among 2923 patients who underwent gastroscopy, the five most common abnormal endoscopic results were as follows (Table 1): Chronic gastritis (95.11\%), peptic ulcers (17.45\%), duodenitis (9.17\%), esophagitis (8.96\%), and polyps (7.42\%). Raised lesions were examined in 70 cases $(2.39 \%)$. Diseases such as gastric retention $(0.44 \%)$, esophageal varices $(0.24 \%)$, and ectopic pancreas $(0.17 \%)$ were rare (Table 1).

\section{Analysis of factors related to abnormal upper gastrointestinal endoscopic results}

Relationship between abnormal upper gastrointestinal endoscopic results and sex

\section{Relationship between chronic gastritis and sex}

Among 2780 cases of chronic gastritis, there were 1635 men and 1145 women (95.17 and $95.02 \%$, respectively) (Table 2). The occurrence of chronic gastritis was higher in men than in women, although the difference was not significant $\left(x^{2}=0.03, p=0.862\right)$.

\section{Relationship between peptic ulcer and sex}

Among 510 cases of peptic ulcers, seven were esophageal ulcers and the remainder were gastric and duodenal ulcers. Peptic ulcers occurred in 376 men and 134 women (21.89 and $11.12 \%$, respectively) (Table 2). The occurrence of peptic ulcer was higher in men than in women $\left(x^{2}=56.988, p=0.000\right)$.

\section{Relationship between polyps and sex}

Among 217 patients with polyps, there were 102 men and 115 women (5.94 and 9.54\%, respectively) (Table 2). The occurrence of polyps was higher in women than in men $\left(\chi^{2}=13.403, p=0.000\right)$.
Table 1 Distribution of lesions detected in the upper gastrointestinal tract

\begin{tabular}{ll}
\hline $\begin{array}{l}\text { Abnormal upper gastrointestinal endoscopic } \\
\text { results }\end{array}$ & $\begin{array}{l}\text { Number } \\
\text { of cases } \\
\text { detected (\%) }\end{array}$ \\
\hline Chronic gastritis & $2780(95.11)$ \\
Peptic ulcers & $510(17.45)$ \\
Duodenitis & $268(9.17)$ \\
Esophagitis & $262(8.96)$ \\
Polyps & $217(7.42)$ \\
Raised lesions to be examined & $70(2.39)$ \\
Esophageal papilloma & $36(1.23)$ \\
Gastric retention & $13(0.44)$ \\
Esophageal leiomyoma & $11(0.38)$ \\
Upper gastrointestinal diverticulum & $10(0.34)$ \\
Gastric cancer & $9(0.31)$ \\
Esophageal varices & $7(0.24)$ \\
Ectopic pancreas & $5(0.17)$ \\
Achalasia & $4(0.14)$ \\
Esophageal cancer & $3(0.10)$ \\
Gastric lymphoma & $2(0.07)$ \\
Heterosis of esophagus and stomach mucosa & $1(0.03)$ \\
Esophageal glycogenic acanthosis & $1(0.03)$ \\
\hline
\end{tabular}

Relationship between abnormal upper gastrointestinal endoscopic results and age Relationship between peptic ulcer and age

A total of 510 patients with peptic ulcers were identified (Table 3); the occurrence of peptic ulcer gradually decreased with increasing age. We made independent comparisons between each age group (Table 3), and we adjusted $\alpha^{\prime}$ to $0.005\left(\alpha^{\prime}=2 \alpha /(k(k-1))\right.$ according to the Bonferroni correction [7]. There were no significant differences among the age groups $(p>0.005)$. The age groups were further divided into an age group of $<30$ years and one of $\geq 30$ years (Table 3 ). The detection rates of these two groups were 24.46 and $16.98 \%$ respectively, with a statistically significant difference between these two groups $\left(x^{2}=6.697, p=0.012\right)$. Peptic ulcers occurred more frequently in the age group $<30$ years than in people $\geq 30$ years.

\section{Relationship between polyps and age}

There were 175 patients with polyps in the <60years age group $(6.83 \%)$ and 42 in the $\geq 60$ years age group $(11.63 \%)\left(x^{2}=10.624, p=0.002\right.$; Table 3$)$. The detection rate of polyps was higher in the $\geq 60$ years age group than in the $<60$ years age group. 
Table 2 Relationship between abnormal upper gastrointestinal endoscopic results and sex

\begin{tabular}{|c|c|c|c|c|c|}
\hline \multirow[t]{2}{*}{ Sex } & \multicolumn{2}{|c|}{ Gastroscopy results } & \multirow[t]{2}{*}{ Total } & \multirow[t]{2}{*}{$x^{2}$} & \multirow[t]{2}{*}{$P$-value } \\
\hline & Chronic gastritis & Non-chronic gastritis & & & \\
\hline Male & 1635 & 83 & 1718 & & \\
\hline Female & 1145 & 60 & 1205 & 0.03 & 0.862 \\
\hline Total & 2780 & 143 & 2923 & & \\
\hline \multirow[t]{2}{*}{ Sex } & \multicolumn{2}{|c|}{ Gastroscopy results } & Total & $x^{2}$ & $P$-value \\
\hline & Peptic ulcer & Non-peptic ulcer & & & \\
\hline Male & 376 & 1342 & 1718 & & \\
\hline Female & 134 & 1071 & 1205 & 56.988 & 0.000 \\
\hline Total & 510 & 2413 & 2923 & & \\
\hline \multirow[t]{2}{*}{ Sex } & \multicolumn{2}{|c|}{ Gastroscopy results } & \multirow[t]{2}{*}{ Total } & \multirow[t]{2}{*}{$x^{2}$} & \multirow[t]{2}{*}{$P$ value } \\
\hline & Polyps & Non-polyps & & & \\
\hline Male & 102 & 1616 & 1718 & & \\
\hline Female & 115 & 1090 & 1205 & 13.403 & 0.000 \\
\hline Total & 217 & 2706 & 2923 & & \\
\hline
\end{tabular}

Table 3 Relationship between abnormal upper gastrointestinal endoscopic results and age

\begin{tabular}{|c|c|c|c|c|}
\hline \multirow[t]{2}{*}{ Age } & \multicolumn{2}{|c|}{ Gastroscopy results } & \multirow[t]{2}{*}{$x^{2}$} & \multirow[t]{2}{*}{$P$ value } \\
\hline & Peptic ulcer & Non-peptic ulcer & & \\
\hline 30-39 years & 89 & 373 & 1.053 & 0.310 \\
\hline 40-49 years & 188 & 912 & & \\
\hline 30-39 years & 89 & 373 & 1.510 & 0.221 \\
\hline $50-59$ years & 135 & 681 & & \\
\hline 30-39 years & 89 & 373 & 2.981 & 0.094 \\
\hline 60 years and above & 53 & 308 & & \\
\hline 40-49 years & 188 & 912 & 0.100 & 0.758 \\
\hline $50-59$ years & 135 & 681 & & \\
\hline $40-49$ years & 188 & 912 & 1.146 & 0.290 \\
\hline 60 years and above & 53 & 308 & & \\
\hline $50-59$ years & 135 & 681 & 0.647 & 0.639 \\
\hline 60 years and above & 53 & 308 & & \\
\hline Under 30 years & 45 & 139 & 6.697 & 0.012 \\
\hline 30 years and above & 465 & 2274 & & \\
\hline \multirow[t]{2}{*}{ Age } & \multicolumn{2}{|c|}{ Gastroscopy results } & $x^{2}$ & $P$ value \\
\hline & Polyps & Non-polyps & & \\
\hline Under 30 years & 19 & 165 & 2.406 & 0.144 \\
\hline 30 years and above & 198 & 2541 & & \\
\hline Under 40 years & 57 & 589 & 2.364 & 0.126 \\
\hline 40 years and above & 160 & 2117 & & \\
\hline Under 50 years & 137 & 1609 & 1.127 & 0.314 \\
\hline 50 years and above & 80 & 1097 & & \\
\hline Under 60 years & 175 & 2387 & 10.624 & 0.002 \\
\hline 60 years and above & 42 & 319 & & \\
\hline
\end{tabular}


Relationship between abnormal upper gastrointestinal endoscopic results and $\mathrm{Hp}$ infection

Relationship between chronic gastritis and Hp infection

Among the 2923 patients who underwent medical examinations, a total of 976 were tested for Hp infection. There were 306 cases of chronic gastritis and 48 cases of nonchronic gastritis in the Hp-positive group, with detection rates of 34.19 and $59.26 \%$, respectively (Table 4). Positive Hp infection was only present in $34 \%$ of patients with chronic gastritis (statistically significant, $\chi^{2}=17.545$, $p=0.000)$.

\section{Relationship between the extent of gastric mucosal inflammation and $\mathrm{Hp}$ infection in chronic gastritis}

The results of 346 gastric mucosal biopsies as follows: there were 26 cases of mild inflammation and 165 cases of moderate or severe inflammation in the Hp-positive group, with detection rates of 13.61 and $86.39 \%$, respectively. There were 135 cases of mild inflammation and 20 cases of moderate or severe inflammation in the Hp-negative group (87.10 and $12.90 \%$ ) (Table 4). There were significant differences between these two groups $\left(x^{2}=185.708, p=0.000\right)$. The inflammation of gastric mucosa in chronic gastritis was more severe in the Hppositive group than in the Hp-negative group.

\section{Relationship between peptic ulcer and Hp infection}

A total of 976 patients underwent $\mathrm{Hp}$ examination. There were $176 \mathrm{Hp}$-positive and $117 \mathrm{Hp}$-negative cases with peptic ulcers, with detection rates of 49.72 and $18.81 \%$, respectively (Table 4 ). More patients infected with $H p$ also had peptic ulcers (statistically significant, $\left.\chi^{2}=102.583, p=0.000\right)$.

\section{Relationship between polyps and $\mathrm{Hp}$ infection}

A total of 152 patients with polyps underwent Hp examination and 28 patients were Hp positive (18.42\%). A total of 824 patients without polyps underwent $\mathrm{Hp}$ examination and 326 patients were Hp positive (39.56\%) (Table 4). The prevalence of $H p$ infection was higher in the patients in whom no polyps were detected (statistically significant, $\left.\mathrm{X}^{2}=24.815, p=0.000\right)$.

\section{Relationship between pathological types of polyps and Hp infection}

Pathological and $\mathrm{Hp}$ tests were performed in 147 patients with polyps. Because hyperplastic polyps

Table 4 Relationship between abnormal upper gastrointestinal endoscopic results and Helicobacter pylori infection

\begin{tabular}{|c|c|c|c|c|c|}
\hline \multirow[t]{2}{*}{ H. pylori test results } & \multicolumn{2}{|l|}{ Gastroscopy results } & \multirow[t]{2}{*}{ Total } & \multirow[t]{2}{*}{$x^{2}$} & \multirow[t]{2}{*}{$P$-value } \\
\hline & Chronic gastritis & Non-chronic gastritis & & & \\
\hline Positive & 306 & 48 & 354 & & \\
\hline Negative & 589 & 33 & 622 & 17.545 & 0.000 \\
\hline Total & 895 & 81 & 976 & & \\
\hline \multirow[t]{2}{*}{ H. pylori test results } & \multicolumn{2}{|c|}{ The extent of gastric mucosal inflammation } & Total & $x^{2}$ & $P$-value \\
\hline & Mild & Moderate or severe & & & \\
\hline Positive & 26 & 165 & 191 & & \\
\hline Negative & 135 & 20 & 155 & 185.708 & 0.000 \\
\hline Total & 161 & 185 & 346 & & \\
\hline \multirow[t]{2}{*}{ H. pylori test results } & \multicolumn{2}{|l|}{ Gastroscopy results } & Total & $x^{2}$ & P-value \\
\hline & Peptic ulcer & Non-peptic ulcer & & & \\
\hline Positive & 176 & 178 & 354 & & \\
\hline Negative & 117 & 505 & 622 & 102.583 & 0.000 \\
\hline Total & 293 & 683 & 976 & & \\
\hline \multirow[t]{2}{*}{ H. pylori test results } & \multicolumn{2}{|l|}{ Gastroscopy results } & Total & $x^{2}$ & $P$-value \\
\hline & Polyps & Non-polyps & & & \\
\hline Positive & 28 & 326 & 354 & & \\
\hline Negative & 124 & 498 & 622 & 24.815 & 0.000 \\
\hline Total & 152 & 824 & 976 & & \\
\hline \multirow[t]{2}{*}{ H. pylori test results } & \multicolumn{2}{|l|}{ Pathological types of polyps } & Total & $x^{2}$ & $P$-value \\
\hline & Fundic glandular polyps & Inflammatory polyps & & & \\
\hline Positive & 7 & 13 & 20 & & \\
\hline Negative & 76 & 41 & 117 & 9.326 & 0.002 \\
\hline Total & 83 & 54 & 137 & & \\
\hline
\end{tabular}


and adenomatous polyps were detected only rarely, we compared the association between $\mathrm{Hp}$ infection and fundic glandular versus inflammatory polyps, with Hp-positive rates of 8.43 and $24.07 \%$, respectively (Table 4). Patients who tested positive for $\mathrm{Hp}$ were more likely to develop inflammatory polyps than fundic glandular polyps (statistically significant, $x^{2}=9.326, p=0.002$ ).

\section{Relationship between pathological types of polyps and age} Fundic glandular polyps were the most common pathological types of polyps present at all ages, followed by inflammatory polyps; adenomatous polyps were rare (Table 5).

\section{Relationship between pathological types of polyps and distribution of lesions}

We compared the pathological locations between the gastric fundus, gastric body, gastric antrum, and duodenum, and there were significant differences among these groups $\left(\chi^{2}=44.188, p=0.000\right)$ according to Fisher precision testing (Table 6). The pathological types of polyps were associated with the distribution of polyp lesions. Fundic glandular polyps were most prevalent in the gastric fundus and gastric body, while inflammatory polyps were most prevalent in the gastric antrum and duodenum.

\section{Discussion}

Our study provided valuable data based on a large population of healthy individuals (without digestive symptoms) undergoing a check-up, revealing solid data regarding the incidence of abnormal upper gastrointestinal endoscopic results. In addition, we indicated an association between abnormal upper gastrointestinal endoscopic results in healthy people, and sex, age, and Hp infection in Eastern countries. These asymptomatic people, who were found to have abnormal upper gastrointestinal endoscopic results, could undergo preventative treatment in advance; thus, avoiding the development of upper gastrointestinal diseases. We found that the incidence of abnormal upper gastrointestinal endoscopic results was high in healthy asymptomatic people. This incidence was associated with sex, age, and $H p$ infection. In addition, the pathological results of polyps depended on the location of the lesion. These data suggest that gastroscopy should form part of a routine health check.

Gastroscopy plays a major clinical role in the diagnosis of gastric diseases. The detection and diagnosis of upper gastrointestinal diseases through gastroscopic intervention was the most routine procedure $[8,9]$. The development of endoscopic technology has led to an increase in the diagnostic rate of early gastric cancer. Several studies indicated a relationship between upper gastrointestinal diseases and associated factors in symptomatic patients, while the associations of abnormal upper gastrointestinal

Table 5 Relationship between pathological types of polyps and age

\begin{tabular}{|c|c|c|c|c|c|}
\hline Age & $\begin{array}{l}\text { Fundic glandular } \\
\text { polyps }\end{array}$ & Inflammatory polyps & Hyperplastic polyps & Adenomatous polyps & Total \\
\hline Under 30 years & 11 & 6 & 1 & 0 & 18 \\
\hline 30-39 years & 15 & 13 & 2 & 0 & 30 \\
\hline $40-49$ years & 30 & 23 & 1 & 0 & 54 \\
\hline $50-59$ years & 15 & 5 & 3 & 1 & 24 \\
\hline 60 years and above & 12 & 7 & 1 & 1 & 21 \\
\hline Total & 83 & 54 & 8 & 2 & 147 \\
\hline
\end{tabular}

Table 6 The correlation between pathological types of polyps and the distribution of lesions

\begin{tabular}{|c|c|c|c|c|c|c|}
\hline & $\begin{array}{l}\text { Fundic glandular } \\
\text { polyps }\end{array}$ & Inflammatory polyps & Hyperplastic polyps & Adenomatous polyps & Total & $P$-value \\
\hline Gastric fundus & 37 & 18 & 2 & 1 & 58 & \\
\hline Gastric body & 42 & 9 & 4 & 0 & 55 & \\
\hline Gastric antrum & 2 & 13 & 1 & 0 & 16 & 0.000 \\
\hline Duodenum & 2 & 14 & 1 & 1 & 18 & \\
\hline Total & 83 & 54 & 8 & 2 & 147 & \\
\hline
\end{tabular}


endoscopic results in asymptomatic healthy people with sex, age, and $\mathrm{Hp}$ infection remained unclear.

We found that chronic gastritis was the most common abnormal upper gastrointestinal endoscopic result detected in healthy asymptomatic people undergoing a medical checkup, followed by peptic ulcer, duodenitis, esophagitis, and polyps. Chronic gastritis, a chronic inflammatory condition of the gastric mucosa, was one of the most common findings of endoscopy in the general population of Eastern countries [10]. According to the classification and grading criteria of chronic gastritis proposed by the Chinese Society of Digestive Endoscopy [11], chronic gastritis was classified as superficial gastritis, erosive gastritis, and atrophic gastritis according to endoscopic appearance. Each type of gastritis was further classified as mild, moderate, or severe depending on the extent of severity. In the present study, we found that the positivity rate of $\mathrm{Hp}$ infection in the group of chronic gastritis was lower than that of patients without chronic gastritis. This may be because of the impact of environmental factors such as a high-salt diet and smoking, as well as the effect of host genetic factors that could cause chronic gastritis in addition to Hp infection [12]. Another study demonstrated that the reason some individuals developed more severe gastritis and progress to disease was multifactorial and included infection by more virulent strains of $\mathrm{Hp}$ [13], this could explain our finding that inflammation of the gastric mucosa in chronic gastritis was more severe in the Hp-positive group than in the Hpnegative group.

Peptic ulcer disease is a source of significant morbidity and mortality worldwide. Approximately two-thirds of patients with peptic ulcer disease were asymptomatic [14]. A higher peptic ulcer disease incidence is associated with male sex, smoking, and chronic medical conditions $[15,16]$. In addition, $\mathrm{Hp}$ and non-steroidal anti-inflammatory drug use were the causes of the vast majority of peptic ulcers [17]. Peptic ulcer disease has also been found to be associated with increasing age [18]. This is consistent with the results of our study in that more patients infected with $H p$ also had peptic ulcers and the occurrence of peptic ulcer was higher in men than in women. Nevertheless, we found that the detection rate of peptic ulcer decreased with age, and peptic ulcers occurred more frequently in the age group $<30$ years than in those aged $\geq 30$ years. This suggests that the association between peptic ulcers and age is different in asymptomatic healthy people and patients. The detection rate of peptic ulcers decreased with age and people in the age group of $<30$ years should be advised to pay more attention to the possibility of peptic ulcers than people in the other age groups.
Upper gastrointestinal polyps are mainly composed of gastric polyps (GPs), which are considered to be precancerous stages of gastric cancer. The clinical manifestations of GPs were nonspecific, with the majority of polyps occasionally found during gastroscopy examination [19]. It has been reported that the incidence of GPs was higher in women than in men, with a ratio of 1:1.8 to 2.5 [20,21]. There was a difference in the incidence of GPs between the sexes. It has been reported that duodenal fluid reflux, which may cause gastric mucosal hyperplasia and polyps, is more common in women [22]. However, further studies are needed to determine whether genetic factors, hormones, and other factors might cause differences in GPs between the sexes. These results corroborate those in our study in that the detection rate of polyps was higher in women than in men, with a ratio of 1:1.6.

It has been reported that the detection rate of GPs increased with increasing age [23]. All types of GPs showed a clear-cut age-dependent rise [24]. Our data also suggest that the detection rate of polyps in the age group of $\geq 60$ years was higher than that in the age group of $<60$ years. The results of our study suggest that older patients are more likely to suffer from polyps. These findings suggest that the elderly population should be targeted for screening for upper gastrointestinal polyps.

Zheng et al. [22] reported a retrospective study of 2125 patients diagnosed with GP between January 2004 and December 2013, and found that GPs in the gastric antrum and gastric body were the most prevalent in both sexes. Similarly, inflammatory polyps and hyperplastic polyps were the most prevalent in both sexes. However, our results were different because the prevalence of common types of GPs is not the same across different regions of the world. Fundic glandular polyps were the most common type in western countries [25], while hyperplastic polyps were more common in Turkey [26]. In the present study, the most common type of GPs was the fundic glandular polyps followed by inflammatory polyps. Our study also suggests that fundic glandular polyps account for a significant proportion of those found in the gastric fundus and gastric body, and inflammatory polyps account for a significant proportion of those found in the gastric antrum and duodenum. Understanding the occurrence of the various types of GPs is important $[27,28]$ because gastric adenomatous polyps have a high malignancy potential, and a small number of hyperplastic polyps are cancerous.

A previous study reported that Hp infection was significantly less frequent in all subjects with GPs than in controls [23]. This is consistent with our finding that the positivity rate of $\mathrm{Hp}$ in the polyp group was lower than that in the non-polyp group. In another study, it was found that $\mathrm{Hp}$ infection rates in patients with 
inflammatory and hyperplastic GPs were significantly higher than in patients with fundic glandular polyps and adenomatous polyps, suggesting that $\mathrm{Hp}$ infection was associated with the formation of inflammatory and hyperplastic polyps. These results were compatible with those of our study, where Hp infection was more prevalent in the inflammatory polyps group than in the fundic glandular polyps group.

There were some limitations to this study. First, the cross-sectional nature of the survey does not support the assumption of a causal relationship. Second, this study was not a randomized controlled study; because it was a retrospective study using clinical data, complete information was not available on certain baseline data such as weight, body mass index, and serum pepsinogen ratio of the participants. Third, the current study only included healthy people who were referred for a gastroscopy; people without medical insurance or younger people might be less likely to undergo gastroscopy. Fourth, not all cases had both a completed pathological examination and the Hp tests. Fifth, the study was conducted in a tertiary endoscopic center, so the possibility of a selection bias cannot be ignored.

\section{Conclusion}

In summary, since the results of the present study showed that the incidence of abnormal upper gastrointestinal endoscopic results is high in healthy people undergoing a check-up, as well as indicated an association between abnormal upper gastrointestinal endoscopic results in healthy people, and sex, age and Hp infection, we suggest that gastroscopy be part of a routine medical examination for healthy subjects. Periodic physical examination is an effective way to monitor and manage physical health.

\section{Abbreviations}

Hp: Helicobacter pylori; UBT: urea breath test; GPS: gastric polyps.

\section{Acknowledgements}

The authors thank the health examination center of Xiangya Hospital who helped with data collection.

\section{Authors' contributions}

HSH conceived the study; HSH, YTR, MW, ZMG, LY, and YHY participated in the study design; HSH, YTR, XXC, JJD, and ZPL collected the data; HSH and HYW performed the statistical analyses; $\mathrm{HSH}$ and YTR drafted the manuscript; JP edited and checked the manuscript. All the authors have read and approved the final manuscript.

\section{Funding}

This study was funded by the National Natural Science Foundation of China under Grant No. 81670589

\section{Availability of data and materials}

The datasets used and/or analysed during the current study are available from the corresponding author on reasonable request.

\section{Ethics approval and consent to participate}

The study protocol was approved by the Ethic Committee of the Xiangya Hospital of Central South University (No: 201912541).

\section{Consent for publication \\ Not applicable.}

\section{Competing interests}

None.

Received: 21 April 2020 Accepted: 23 November 2020

Published online: 09 December 2020

References

1. Artandi MK, Stewart RW. The outpatient physical examination. Med Clin North Am. 2018;102(3):465-73.

2. Lopriore S, LeCouteur A, Ekberg K, Ekberg S. "You'll have to be my eyes and ears": a conversation analytic study of physical examination on a health helpline. J Clin Nurs. 2019;28:330-9.

3. Wong HM, Yang W, Yang J, Wang C. The value of routine gastroscopy before laparoscopic Roux-en-Y gastric bypass surgery in Chinese patients. Surg Obes Relat Dis. 2015;11:303-7.

4. Wang YK, Kuo FC, Liu CJ, Wu MC, Shih HY, Wang SS, et al. Diagnosis of helicobacter pylori infection: current options and developments. World J Gastroenterol. 2015;21(40):11221-35.

5. Tytgat GN. The Sydney system: endoscopic division. Endoscopic appearances in gastritis/duodenitis. J Gastroenterol Hepatol. 1991;6:223-34.

6. Fang JY, Du YQ, Liu WZ, Ren JL, Li YQ, Chen XY, et al. Chinese consensus on chronic gastritis (2017, Shanghai). J Dig Dis. 2018;19(4):182-203.

7. Andrade C. Multiple testing and protection against a type 1 (false positive) error using the Bonferroni and Hochberg corrections. Indian J Psychol Med. 2019;41(1):99-100.

8. Shi C, Xue Y, Jiang C, Tian H, Liu B. Gastroscopic panoramic view: application to automatic polyps detection under gastroscopy. Comput Math Methods Med. 2019;2019:4393124.

9. Men F, Wei L, Liu B, Wu F, Liu J, Guo N, et al. Comparison of the safety of the application of painless gastroscopy and ordinary gastroscopy in chronic hypertension patients combined with early gastric cancer. Oncol Lett. 2018;15(3):3558-61.

10. Bai Y, Li ZS, Zou DW, Wu RP, Yao YZ, Jin ZD, et al. Alarm features and age for predicting upper gastrointestinal malignancy in Chinese patients with dyspepsia with high background prevalence of Helicobacter pylori infection and upper gastrointestinal malignancy: an endoscopic database review of 102665 patients from 1996 to 2006. Gut. 2010;59(6):722-8.

11. Rugge M, Correa P, Dixon MF, Hattori T, Leandro G, Lewin K, et al. Gastric dysplasia: the Padova international classification. Am J Surg Pathol. 2000;24:167-76.

12. Dhar P, Ng GZ, Sutton P. How host regulation of helicobacter pyloriinduced gastritis protects against peptic ulcer disease and gastric cancer. Am J Physiol Gastrointest Liver Physiol. 2016;311:G514-20.

13. Wroblewski LE, Peek RM, Wilson KT. Helicobacter pylori and gastric cancer: factors that modulate disease risk. Clin Microbiol Rev. 2010;23:713-39.

14. Kavitt RT, Lipowska AM, Anyane-Yeboa A, Gralnek IM. Diagnosis and treatment of peptic ulcer disease. Am J Med. 2019;132(4):447-56.

15. Garrow D, Delegge MH. Risk factors for gastrointestinal ulcer disease in the US population. Dig Dis Sci. 2010;55(1):66-72.

16. Rosenstock S, Jorgensen T, Bonnevie O, Andersen L. Risk factors for peptic ulcer disease: a population based prospective cohort study comprising 2416 Danish adults. Gut. 2003;52(2):186-93.

17. Kurata JH, Nogawa AN. Meta-analysis of risk factors for peptic ulcer. Nonsteroidal antiinflammatory drugs, helicobacter pylori, and smoking. Clin Gastroenterol. 1997;24(1):2-17. 
18. Kang JY, Tinto A, Higham J, Majeed A. Peptic ulceration in general practice in England and Wales 1994-98: period prevalence and drug management. Aliment Pharmacol Ther. 2002;16(6):1067-74.

19. Wang HB, Xu L. Analysis on the clinical characteristics of gastric polyps in elderly patients. Chin J Geriatr. 2010;29(5):390-3.

20. Cao H, Wang B, Zhang Z, Zhang H, Qu R. Distribution trends of gastric polyps: an endoscopy database analysis of 24121 northern Chinese patients. J Gastroenterol Hepatol. 2012;27(7):1175-80.

21. Yoon WJ, Lee DH, Jung YJ, Jeong JB, Kim JW, Kim BG, et al. Histologic characteristics of gastric polyps in Korea: emphasis on discrepancy between endoscopic forceps biopsy and endoscopic mucosal resection specimen. World J Gastroenterol. 2006;12(25):4029-32.

22. Zheng E, Ni S, Yu Y, Wang Y, Weng X, Zheng L. Impact of gender and age on the occurrence of gastric polyps: data analysis of 69575 southeastern Chinese patients. Turk J Gastroenterol. 2015;26(6):474-9.

23. Archimandritis A, Spiliadis C, Tzivras M, Vamvakousis B, Davaris P, Manika $Z$, et al. Gastric epithelial polyps: a retrospective endoscopic study of 12974 symptomatic patients. Ital J Gastroenterol. 1996;28(7):387-90.

24. Sonnenberg A, Genta RM. Prevalence of benign gastric polyps in a large pathology database. Dig Liver Dis. 2014;47(2):164-9.
25. Carmack SW, Genta RM, Schuler CM, Saboorian MH. The current spectrum of gastric polyps: a 1-year national study of over 120,000 patients. Am J Gastroenterol. 2009;104:1524-32.

26. Kekilli M, Beyazit Y, Karaman K, Sayilir A, Kurt M, Onal IK, et al. Endoscopic and pathological aspects of gastric polyps: a Turkish referral center study. Hepatogastroenterology. 2012;59:1147-9.

27. Kelly PJ, Lauwers GY. Clinical guidelines: consensus for the management of patients with gastric polyps. Nat Rev Gastroenterol Hepatol. 2011;8:7-8.

28. Dirschmid K, Platz-Baudin C, Stolte M. Why is the hyperplastic polyp a marker for the precancerous condition of the gastric mucosa? Virchows Arch. 2006:448:80-4.

\section{Publisher's Note}

Springer Nature remains neutral with regard to jurisdictional claims in published maps and institutional affiliations.
Ready to submit your research? Choose BMC and benefit from:

- fast, convenient online submission

- thorough peer review by experienced researchers in your field

- rapid publication on acceptance

- support for research data, including large and complex data types

- gold Open Access which fosters wider collaboration and increased citations

- maximum visibility for your research: over $100 \mathrm{M}$ website views per year

At BMC, research is always in progress.

Learn more biomedcentral.com/submissions 